\title{
Measuring Urban Subsidence in the Rome Metropolitan Area (Italy) with Sentinel-1 SNAP-StaMPS Persistent Scatterer Interferometry
}

\author{
José Manuel Delgado Blasco ${ }^{1, *}$, Michael Foumelis ${ }^{2}$, Chris Stewart ${ }^{3}$ and Andrew Hooper ${ }^{4}$ \\ 1 Grupo de Investigación Microgeodesia Jaén (PAIDI RNM-282), Universidad de Jaén, 23071 Jaén, Spain \\ 2 BRGM-French Geological Survey, 45060 Orleans, France; M.Foumelis@brgm.fr \\ 3 Future Systems Department, Earth Observation Programmes, European Space Agency (ESA), \\ 00044 Frascati, Italy; chris.stewart@esa.int \\ 4 Institute of Geophysics and Tectonics, University of Leeds, Leeds LS2 9JT, UK; A.Hooper@leeds.ac.uk \\ * Correspondence: j.dblasco@ujaen.es
}

Received: 30 November 2018; Accepted: 8 January 2019; Published: 11 January 2019

\begin{abstract}
Land subsidence in urban environments is an increasingly prominent aspect in the monitoring and maintenance of urban infrastructures. In this study we update the subsidence information over Rome and its surroundings (already the subject of past research with other sensors) for the first time using Copernicus Sentinel-1 data and open source tools. With this aim, we have developed a fully automatic processing chain for land deformation monitoring using the European Space Agency (ESA) SentiNel Application Platform (SNAP) and Stanford Method for Persistent Scatterers (StaMPS). We have applied this automatic processing chain to more than 160 Sentinel-1A images over ascending and descending orbits to depict primarily the Line-Of-Sight ground deformation rates. Results of both geometries were then combined to compute the actual vertical motion component, which resulted in more than 2 million point targets, over their common area. Deformation measurements are in agreement with past studies over the city of Rome, identifying main subsidence areas in: (i) Fiumicino; (ii) along the Tiber River; (iii) Ostia and coastal area; (iv) Ostiense quarter; and (v) Tivoli area. Finally, post-processing of Persistent Scatterer Inteferometry (PSI) results, in a Geographical Information System (GIS) environment, for the extraction of ground displacements on urban infrastructures (including road networks, buildings and bridges) is considered.
\end{abstract}

Keywords: urban subsidence; Copernicus Sentinel-1; Persistent Scatterer Interferometry; SNAP-StaMPS; Rome

\section{Introduction}

Since the launch of Copernicus Sentinel-1A on 8 April 2014, a new era of continuous monitoring using spaceborne Synthetic Aperture Radar (SAR) sensors has started. Sentinel-1 constitutes a significant improvement from previous European C-band SAR missions, European Remote Sensing (ERS) satellites and Environmental Satellite (ENVISAT), since it reduced the temporal revisit time from 35 to six days, at best using the two satellite segments A and B, with a large swath coverage of $250 \mathrm{~km}$. The scientific communities as well as Earth Observation (EO) practitioners were thus given the means to extend the use of spaceborne SAR data to land applications.

In support to the EO community, the European Space Agency (ESA) continued developing appropriate tools for the utilization of the Copernicus Sentinel data. By evolving existing tools, such as the Next ESA SAR Toolbox (NEST) as well as integrating others, the SeNtinel Application Platform (SNAP) [1] becomes a multi-mission toolbox supporting both SAR and optical data processing. 
Newly implemented on Sentinel-1, the Terrain Observation by Progressive Scans (TOPS) acquisition mode [2] required further development in terms of interferometric handling to ensure robust results. The SNAP TOPSAR) capabilities were made available to users at an early stage, just before the start of Sentinel-1 data dissemination, while SNAP TOPS Interferometric SAR (InSAR) development were first communicated at the ESA Fringe 2015 consultation meeting. Currently, TOPS InSAR processing is sufficiently documented [3-7] and SNAP remains a widely used end-to-end open source tool for processing of Sentinel-1 data.

Further development of SNAP was carried out to include exports to software packages supporting more advanced interferometric analysis, such as Stanford Method for Persistent Scatterers (StaMPS) [8]. StaMPS is a freely distributed package for research purposes with a large user community that incorporates Persistent Scatterer Interferometry (PSI) and Small Baseline methods to measure ground displacements from time series of SAR acquisitions. The idea was for the open source InSAR processor to be used together with StaMPS PSI, boosting the utilization of the Copernicus Sentinel-1 data for geohazard-related applications. The potential of SNAP-StaMPS integration has been already demonstrated at [9], for which the authors had also published a set of scripts to support utilization by the scientific community [10].

In this study we employ such open tools to analyze the urban deformation of the Rome metropolitan area for the first time using Sentinel-1 data, and combined ascending and descending orbits to depict the vertical urban deformation with special attention to different areas. Ground deformation analyses of Rome have already been undertaken in the past [11,12], but these have not been updated recently, and have not included Sentinel-1 SAR observations. Here we intend to update existing knowledge with contemporary information regarding ground deformation in the Rome metropolitan area using open data and tools. Previous relevant studies are indirectly used to verify our findings and to allow us to understand which subsidence patterns correspond to already identified phenomena and which new sources of deformation that would require further attention. Finally, a dedicated analysis was performed highlighting vertical displacements along urban infrastructures, including road networks, buildings and bridges.

\subsection{Study Area}

The study area includes the city of Rome and its surroundings, in the Lazio region of central Italy (Figure 1). The geology of the region is characterized by volcanic deposits (mainly pyroclastic tuff) from the Albano volcano district to the southeast and the Sabatino volcano district to the northwest, with alluvial sediments along the Tiber valley in between the two [13]. The topography gradually decreases from these two volcanic districts towards the Tiber, with valleys carved by fluvial erosion. The variability of heights in the Rome metropolitan plain does not exceed $100 \mathrm{~m}$.

The southwest of the study area is dominated by the Tiber River delta and coastal plain. Both are comprised of alluvial sediments with a flat morphology [12]. The northeast of the study area includes the beginning of the Apennines mountain chain, comprising mainly sedimentary limestone and dolomite rocks [13].

Many cases of land subsidence have already been identified over the study area, and quantified through various InSAR techniques, a detailed review of which is presented in [14]. Subsidence of buildings on the alluvial sediments along the Tiber River in Rome has been measured using PSI, Small Baseline Subsets (SBAS), Interferometric Point Target Analysis (IPTA) and 4D SAR imaging techniques in many studies, e.g., by [11,15-17] and others, using ERS-1, 2 and ENVISAT ASAR data. The main cause of subsidence in this case is the weight of relatively recent construction on the unconsolidated alluvial material, especially in areas such as Grotta Perfetta, in the southwestern outskirts of the city [11-16].

Other studies, such as $[14,18,19]$, focused on quantifying displacement which may affect the structural integrity of archaeological monuments in the historical center of the city, using SBAS, PSI 
and SqueeSAR with ERS-1 and -2, ENVISAT ASAR [18], Radarsat-1, 2 [19] and COnstellation of small Satellites for the Mediterranean basin Observation (COSMO-SkyMed) data [14].

Another type of ground displacement in the region of interest, which has been measured using InSAR techniques, has been identified in the Acque Albule Plain [20], in the northeastern part of the study area. Here a combination of groundwater extraction for mining and the presence of compressible soils has led to ground subsidence in the area. This has been quantified and studied with ERS and ENVISAT data using PSI and Quasi-PS InSAR (QPS) techniques by [21]. QPS is based on a different set of filtered interferograms (multi-master configuration) and is weighted by interferometric coherence.

More recently, subsidence affecting the area surrounding the Rome Fiumicino (FCO) airport, in particular over the third runway, has been studied with the PSI technique applied to ERS, ENVISAT and COSMO-SkyMed data by [12]. The authors showed how the varying rate of subsidence in the area correlates with the age of overlying man-made constructions and the nature of the underlying geology.

\section{Materials and Methods}

\subsection{Open Source Toolboxes}

This work has been carried out using the open source ESA SNAP and StaMPS software packages. The SNAP Graph Builder operator can be used to create processing chains which can be called using the batch mode Graph Processing Tool (GPT). We have exploited this utility to create the several templates necessary for creating single master TOPSAR coregistration and interferogram generation.

Finally, in order to fully automate the single master interferogram generation, we have developed and made available, based on well-designed SNAP graphs, a set of scripts called "snap2stamps". These scripts enable automatic processing after setting some parameters in a configuration file. In fact, they are python wrappers which use the aforementioned templates based mainly on SNAP TOPSAR interferometric operators and whose outputs are compatible with StaMPS PSI chain. The snap2stamps scripts are available via the Zenodo repository [10]. Latest versions of the scripts (not verified by the developing team) can also be found on the GitHub repository (https:/ / github.com/mdelgadoblasco/ snap2stamps). The authors had released a first version of the snap2stamps package in July 2018, which automates the TOPSAR single master Differential InSAR (DInSAR) processing, fully compatible with StaMPS PSI [9], allowing the creation of stacks of single master interferograms in batch mode, just by defining some simple settings such as project folder, subswath to process and defining the bounding box coordinates of the area of interest.

Additionally, for the removal of the Atmospheric Phase Screen (APS), we have employed the Toolbox for Reducing Atmospheric InSAR Noise (TRAIN) [22] and applied the linear approach (topography versus phase) integrated in the aforementioned open source package.

\subsection{Data and Processing}

For the data processing we have employed an ESA RSS CloudToolbox which is a Virtual Machine provided by the ESA Research and Service Support [23] with access to collocated Sentinel-1 data via Copernicus Data and Information Access Services (DIAS). This has the advantage of eliminating the data download time, as the data is locally accessible and ready to use. The resources employed were $8 \mathrm{vCPUs}, 32$ GB RAM and 1TB disk space, resulting in a total processing time of approximately 15 days, including the post-analysis of PSI results.

For the interferometric processing, the Advanced Land Observation Satellite (ALOS) World 3D (AW3D30) Digital Surface Model (DSM) [24], of $30 \mathrm{~m}$ spatial resolution, was utilized, while for examining the geolocation accuracy as well as the interpretation of PSI results we employed a very high resolution DSM (5 m/pixel), as extracted from CartoSat-1 satellite data [25]. 


\subsubsection{Copernicus Sentinel-1 Data}

We limited our analysis to Sentinel-1A data only (12-days repeat cycle) (Table 1), which is sufficient given the expected magnitude of ground displacements and the availability of a large number of acquisitions over the area of interest. Some details on the Sentinel-1 data employed for the processing are shown in Table 1. It should be noted that since Sentinel-1 products are not spatially synchronized, meaning that their starting and ending times may vary within each orbit, often more than one scene is required to fully cover our area of interest. This introduces additional storage and computational requirements, as consecutive scenes, for the same acquisition date, need to be downloaded and assembled into single products before proceeding with the interferometric processing. Our area of interest (AOI) and the extent of Sentinel-1 ascending (A117) and descending (D022) orbits is illustrated in Figure 1.

Among the different options, we have selected ascending and descending tracks, 117 and 022 , respectively, for which the area of interest is mapped with comparable incidence angles. By ensuring combination of similar viewing geometry, i.e., sensitivity to vertical motion, we facilitate a more robust extraction of the vertical motion component, of interest for our investigation.

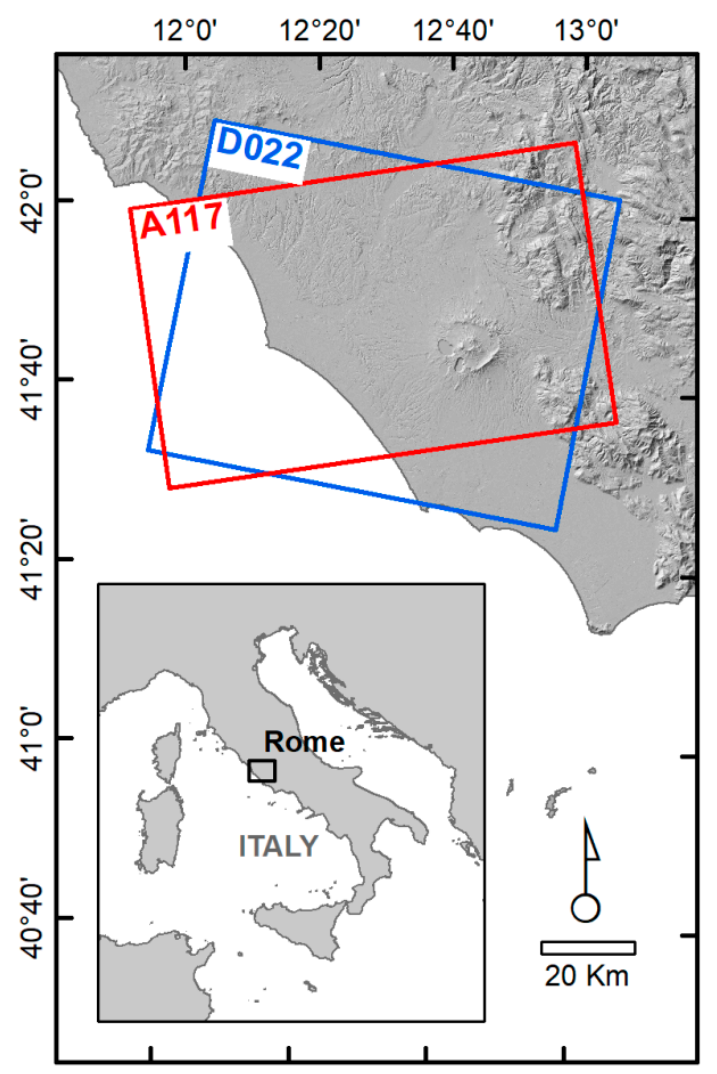

Figure 1. Area of interest and footprint of the selected Sentinel-1 master scenes for both ascending (A117) and descending (D022) tracks. ALOS World 3D DSM used as background.

Table 1. Sentinel-1 data employed for processing, with first and last image of each dataset, orbit pass, track and number of acquisitions.

\begin{tabular}{cccccc}
\hline Satellite & First Image & Last Image & Orbit Pass & Track & N Acquisitions \\
\hline S1A & $2015 / 03 / 24$ & $2018 / 04 / 13$ & Descending & 22 & 82 \\
S1A & $2015 / 03 / 30$ & $2018 / 04 / 19$ & Ascending & 117 & 87 \\
\hline
\end{tabular}




\subsubsection{SNAP-StaMPS PSI Processing}

The PSI processing is split into two independent workflows: (i) single master DInSAR processing using ESA SNAP; and (ii) the PSI processing using StaMPS.

Firstly, the master scene is selected from the beginning of the data series, as Sentinel-1 has orbit control which guarantees any interferometric combination among the data. Additionally, as we want to obtain PS points over urban infrastructure, we expect that temporal baseline will not greatly affect the number of PS obtained. Master image splitting and update of orbit state vectors follow, also using the SNAP Graphical User Interface (GUI), to ensure proper selection of bursts covering our AOI. These steps are critical since they optimize time and resources for the rest of the processing. Table 2 details the parameters involved in master image splitting for burst selection over the AOI.

Table 2. Main characteristics of the selected Sentinel-1A master scene.

\begin{tabular}{ccccccc}
\hline Track & $\begin{array}{c}\text { Acquisition } \\
\text { Date }\end{array}$ & $\begin{array}{c}\text { Mean Inc. Angle } \\
\text { (rad/degrees) }\end{array}$ & Sub-Swath & Polarization & Initial Burst & Last Burst \\
\hline D022 & $2015 / 05 / 23$ & $0.75 / 42.97$ & IW3 & VV & 5 & 8 \\
A117 & $2015 / 08 / 09$ & $0.67 / 38.39$ & IW2 & VV & 5 & 7 \\
\hline
\end{tabular}

The next step involves generating all single master interferograms using the snap2stamps scripts, by following an automatic processing scheme implemented in four steps:

1. Slave preparation. In this step, the Sentinel-1 Single Look Complex (SLC) data are sorted by acquisition date while checking if SLC assembly (concatenation procedure) is necessary, depending on whether the defined $\mathrm{AOI}$ is covered by more than one scene per acquisition date.

2. Slave splitting. To enable processing in batch mode, the SNAP Graph Processing Tool (GPT) is used, which runs already-defined processing chains (graphs in xml format). For this step, the TOPSAR-Splitting and Apply Orbit operators are called, to update the annotated orbit information with more precise ones according to their availability (restituted or precise). These orbits are automatically downloaded by SNAP. The corresponding graph is illustrated in Figure 2, part A.

3. Coregistration and interferogram computation. This is the most computationally demanding step, as it performs the coregistration of the TOPSAR data (Back-geocoding with Enhanced Spectral Diversity [26] refinement) and produces the interferograms with the Flat-Earth and topographic phase contributions removed. Optionally, a finer subset can be applied over an AOI, as defined in the project configuration file. If no information is provided by the user, the full burst interferograms are generated. The outputs of this step are two debursted stacks of master-slave Single Look Complex (SLC) files and the master-slave interferogram. Supplementary data files required by StaMPS are also generated, including elevation band and orthorectified latitude and longitude coordinates as independent products. The graph employed for this step is shown in Figure 2, part B.

4. Stamps export. This is the final step of the single master DInSAR processing, which converts previous processing results into binary raster files compatible with StaMPS readers. Graph shown in Figure 2, part C. 


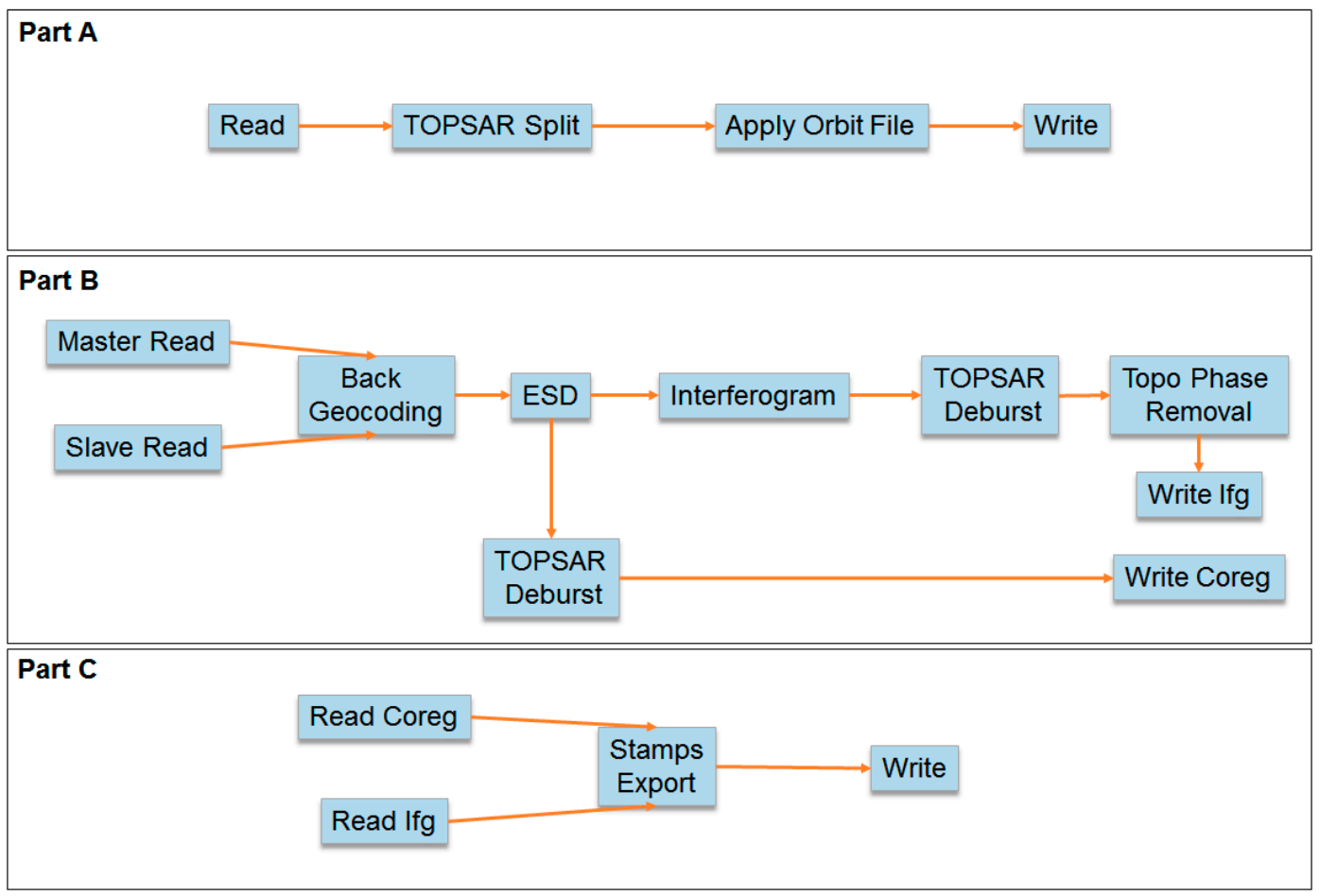

Figure 2. Schematic diagram presenting the different chains of the SentiNel Application Platform (SNAP) workflow to prepare the interferometric inputs for Stanford Method for Persistent Scatterers (StaMPS) Persistent Scatterer Interferometry (PSI) processing [9]. Part (A-C) illustrate the workflow employed for slave splitting, coregistration, interferometric computation and StaMPS export, respectively.

The following step involves the ingestion of SNAP exports into StaMPS using a specific script, called $m t \_p r e p \_s n a p$, available in the distribution. Subsequently, the StaMPS PSI processing chain is run from step 1 to 7 as described in the StaMPS User Manual [27].

In this case, we additionally applied the integrated TRAIN, using the linear tropospheric correction approach, to mitigate the topography-correlated atmospheric phase.

In order to properly merge the results from both ascending and descending tracks in subsequent post-processing steps, we selected the same reference point in both cases, corresponding to a permanent European Reference Frame (EUREF) Global Navigation Satellite System (GNSS) station (MOSE00ITA), located at the Aerospace Engineering Faculty of the University of Rome "La Sapienza". Based on the EUREF solution [28], the station seems stable, with no evident vertical motion ( $\mathrm{Vx}=-0.7 \pm 0.1 \mathrm{~mm} / \mathrm{yr}$, $\mathrm{Vy}=-1.3 \pm 0.1 \mathrm{~mm} / \mathrm{yr}$ and $\mathrm{Vz}=0.5 \pm 0.1 \mathrm{~mm} / \mathrm{yr}$ in ETRF2014) during the entire observation period.

We ran StaMPS PSI three times from the merging of the different patches (step 5) onwards, each time with different grid options [27]: (i) no merging; (ii) merging by $20 \mathrm{~m}$ grid; and (iii) merging by $40 \mathrm{~m}$ grid. For each run, the merging of PS candidates was performed with the same threshold selected for the phase noise filtering in StaMPS step 4.

\subsubsection{Post-Processing}

Having both ascending and descending PSI measurements, we combined them to calculate the vertical component for each individual Persistent Scatter (PS) point (see Figure 3) using Equation (1) and (2), as described in [29]:

$$
\left[\begin{array}{c}
d_{\text {LOS }}{ }^{\text {asc }} \\
d_{\text {LOS }}{ }^{\text {desc }}
\end{array}\right]=A\left[\begin{array}{c}
d_{u p} \\
d_{h_{\text {ald }}}
\end{array}\right]
$$


with

$$
A=\left[\begin{array}{ll}
\cos \theta^{a s c} & \frac{\sin \theta^{a s c}}{\cos \Delta \alpha} \\
\cos \theta^{d e s c} & \sin \theta^{d e s c}
\end{array}\right]
$$

where $d_{\text {LOS }}$ is displacement along Line-Of-Sight (LOS). $d_{u p}$ is the vertical displacement. $d_{\text {hald }}$ is the projection of horizontal displacement in descending azimuth look direction (ALD). $\theta$ is the incident angle. $\Delta \alpha$ is the satellite heading, difference between ascending and descending orbit.
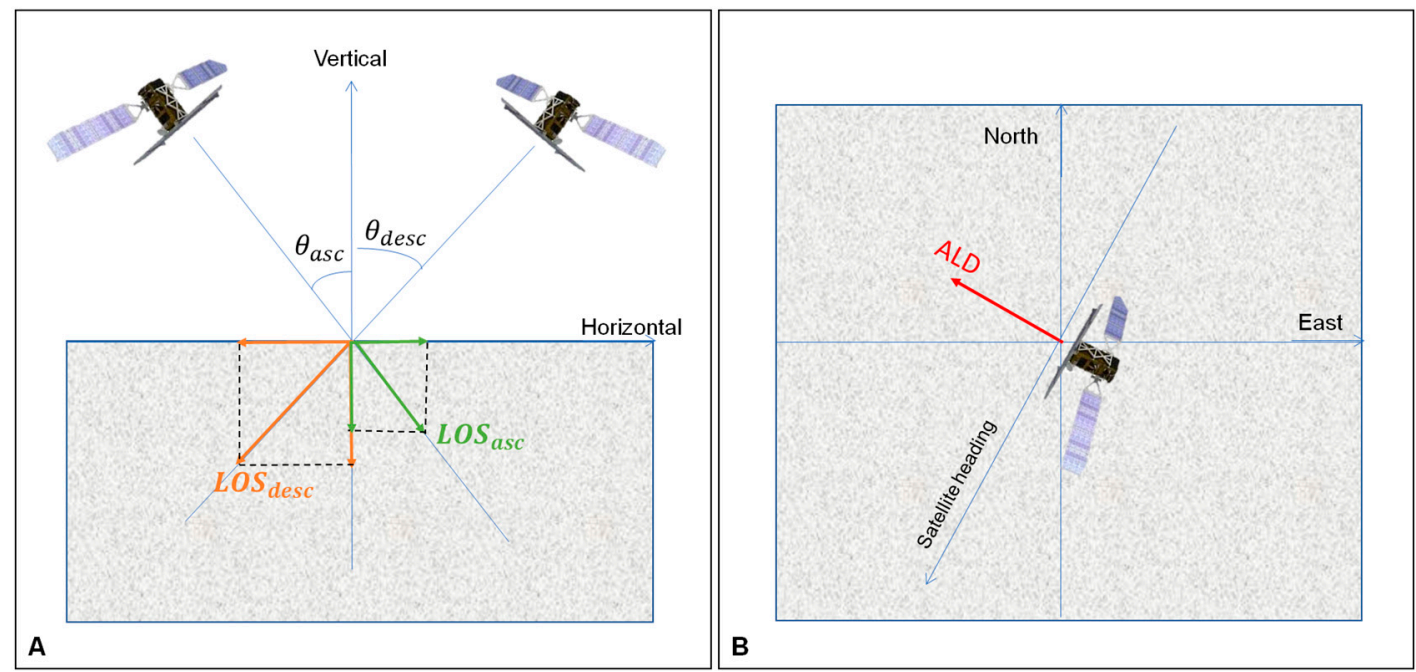

Figure 3. Ascending and descending decomposition in vertical and horizontal components (A) and the Azimuth Look Direction (ALD) for the descending orbit pass (B).

The combination of ascending and descending PS points was performed in the vector domain avoiding any rasterization option, as described in [30]. The method combines PS targets based on their geographic proximity, while attributes transfer and decomposition of motion is done within the features geodatabases. This leads to a higher number of final PS points and reduction of error budget introduced by spatial interpolation and rasterization procedures. PS points of one geometry having no neighbouring targets by the opposite geometry, within a defined search radius, are being excluded. The selection of the maximum search radius for the combination, in our case $40 \mathrm{~m}$, was based on the statistical analysis of the distances between PS targets from the independent LOS solutions.

After obtaining the vertical component of the deformation rates, by using GIS capabilities, we overlaid the deformation information over buildings, roads, highways and railways vector layers to calculate the maximum observed deformation for each of these elements. In such a way, we were able to provide subsidence information over critical infrastructure (roads, bridges etc.) as well as on individual building blocks. For the special case of the road networks, and in order to depict the spatial variability of motion along them, a segmentation procedure was applied considering a distance of $20 \mathrm{~m}$ for each segment. The displacement value is then calculated based on PS points located at a specified distance across each road segment. To reduce overlaps between successive segments, we considered a square buffering option, i.e., buffer zones do not exceed the segments' start and end points.

Since StaMPS does not update PS heights, inaccuracies in the geolocation of PS targets over urban environments, especially for high buildings, might occur. To compensate for the above mentioned issue, during the calculation of the deformation statistics for each vector element (road, buildings etc.) a $20 \mathrm{~m}$ buffer was considered. The choice of the buffer distance was based on the visual interpretation of the results.

\section{Results}

We have obtained the average PSI LOS deformation rates for both ascending and descending tracks (Figure 4). An indicator of the compatibility of solutions between acquisition geometries is the 
standard deviation of the mean LOS deformation velocities, which correspond to $1.04 \mathrm{~mm} / \mathrm{yr}$ and $1.17 \mathrm{~mm} / \mathrm{yr}$ for A117 and D022 tracks, respectively.

Given the difference in area covered by each track, the relatively larger number of PS points in the descending solution could be explained (Table 3). Apart from the effect of area coverage, it seems that the overall numbers of PS points is comparable. We attribute this to the common observation period and incidence angles considered for both ascending and descending datasets.

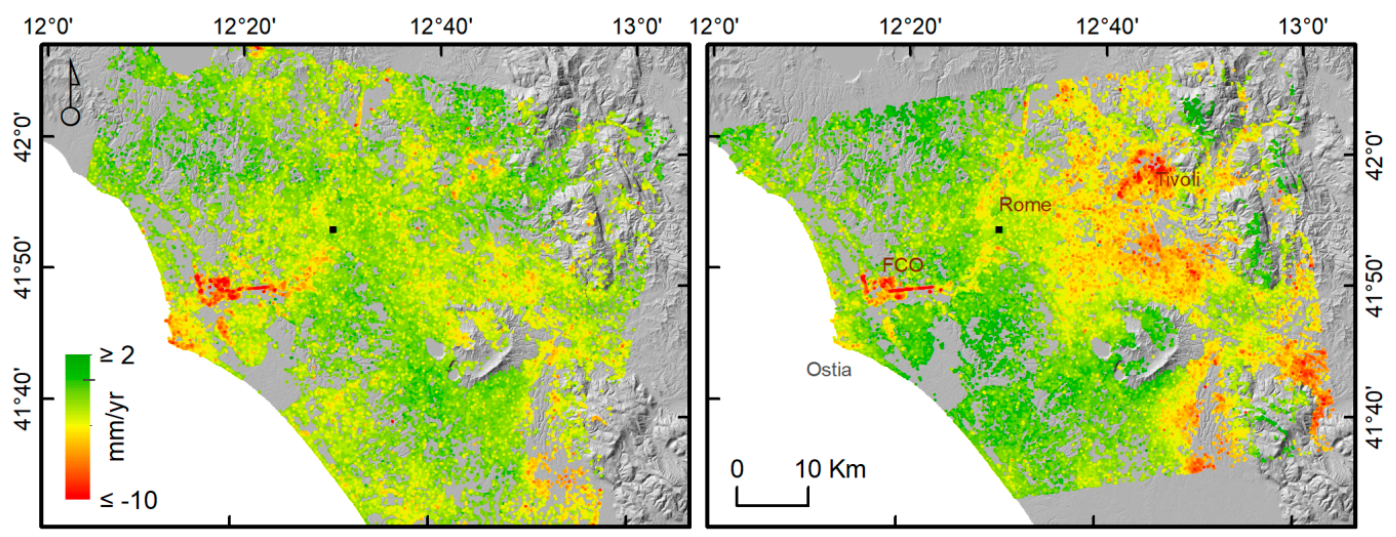

Figure 4. Sentinel-1 average Line-Of-Sight (LOS) deformation rate maps over the period March 2015-April 2018 for descending (left) and ascending (right) acquisition geometries. Positive values indicate motion towards the sensor or uplift, whereas negative values motion away from the sensor or subsidence. Selected reference point (MOSE00ITA EUREF station) is shown as square. ALOS World 3D Digital Surface Model (DSM) as background.

After decomposing the ascending and descending LOS measurements, we obtained the vertical deformation rate map presented in Figure 5. It can be easily seen that various deformation patterns exist, attributed mainly to the different subsidence mechanisms acting in the metropolitan area of Rome. There are several areas undergoing significant subsidence, such as (i) FCO airport; (ii) along the Tiber River; (iii) the coastal zone of Ostia; (iv) Ostiense quarter within Rome and; (v) Tivoli area, while the rest of the region exhibits relatively low ground deformation rates. In the following sections we provide a more detailed analysis of the PSI results.

As we ran StaMPS using different merging options, we obtained different numbers of PS points for each solution. In Table 3, we summarize the total points obtained for each merging configuration and those remaining after the vertical decomposition. It should be noted that, for the decomposition, only the overlapping area between ascending and descending results is exploited.

Table 3. Total number of PS points obtained by StaMPS processing (LOS) and after the decomposition to actual motion component (Vertical).

\begin{tabular}{|c|c|c|c|}
\hline Orbit & $\begin{array}{l}\text { No Merging } \\
\text { LOS/Vertical }\end{array}$ & $\begin{array}{c}20 \mathrm{~m} \\
\text { LOS/Vertical }\end{array}$ & $\begin{array}{c}40 \mathrm{~m} \\
\text { LOS/Vertical }\end{array}$ \\
\hline Ascending (A117) & $1065328 / 947386$ & $486188 / 418481$ & $264024 / 211999$ \\
\hline Descending (D022) & $1342924 / 1061976$ & $580578 / 439738$ & $311615 / 217237$ \\
\hline
\end{tabular}

For the full resolution datasets, we obtained over 1 million point targets for both orbits (Table 3), a fact which poses some difficulties in handling the dataset for post analysis purposes. The decision to reduce the initial number of PS points or not depends actually on the application at hand. For example, while working on infrastructure monitoring, it may be relevant to maintain full resolution results, as the number of points decreases rapidly after merging. For the needs of our work, the $20 \mathrm{~m}$ merged solutions offered a reasonable trade-off between density of PS targets and computational requirements for post-processing. 
The obtained PS density after the decomposition, calculated at $200 \mathrm{~m}$ grid, is shown in Figure 5. The increase of density over the built-up area of Rome, reaching 1700 points $/ \mathrm{km}^{2}$ in the center of the city, is evident, while several rural urban centers also exhibit relatively high PS densities varying from 300 to 600 points $/ \mathrm{km}^{2}$. The locations of ascending and descending PS targets over an urban fabric of moderate density are presented (Figure 6), showing the advantages of the applied decomposition approach in retaining larger numbers of PS targets that allows proper characterization of on-going deformation phenomena. The final average velocity map of vertical deformation over the study area is shown in Figure 5, where the different areas with higher subsidence can be clearly identified.

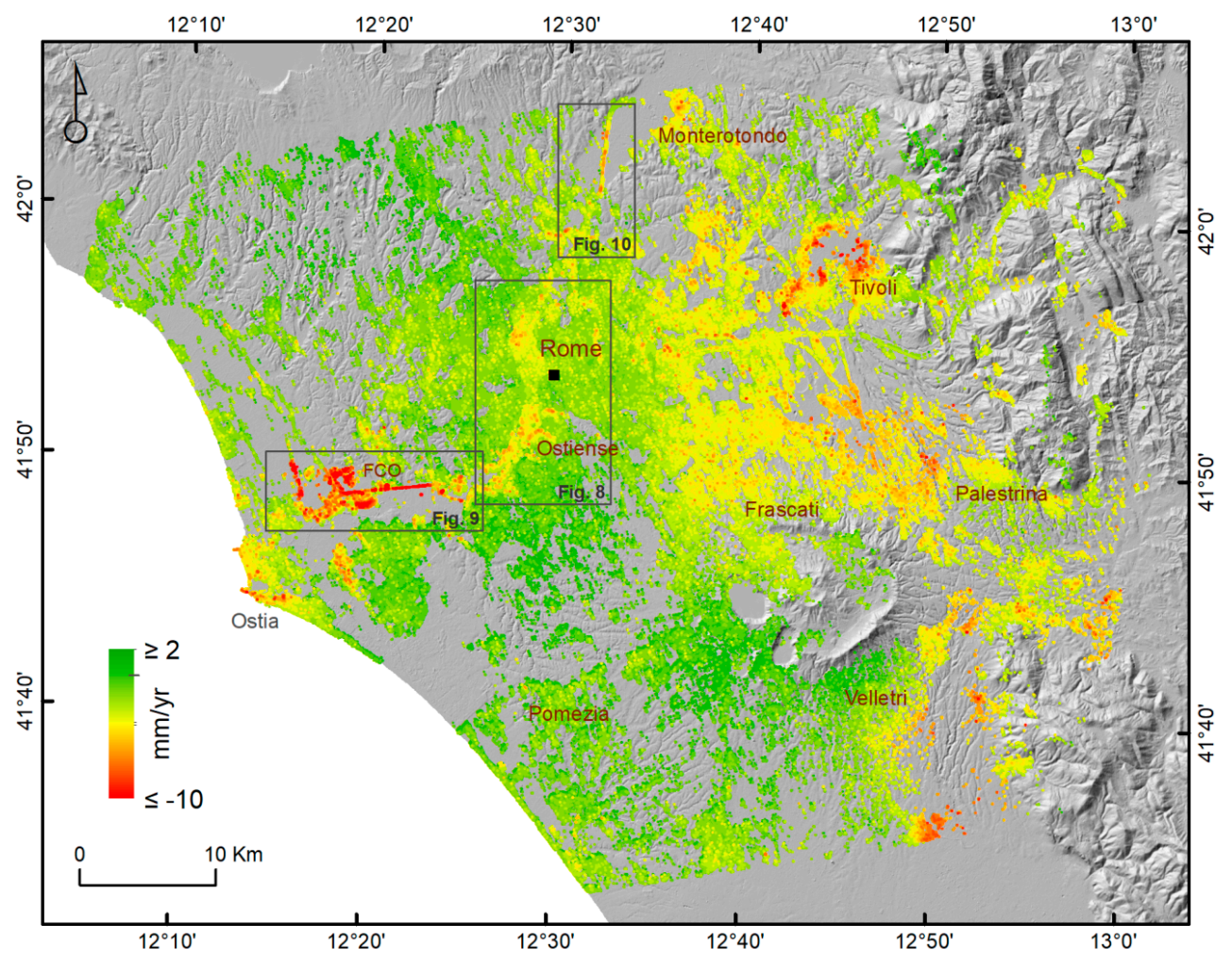

Figure 5. Figure 5. Sentinel-1 average vertical motion rates for the period March 2015-April 2018. For the decomposition, PS points at full resolution were spatially down sampled by a window of $40 \mathrm{~m}$ radius (see Section 2.2.2). Selected reference point (MOSE00ITA EUREF station) is marked by a black square. ALOS World 3D DSM as background. The locations of other figures are also shown.
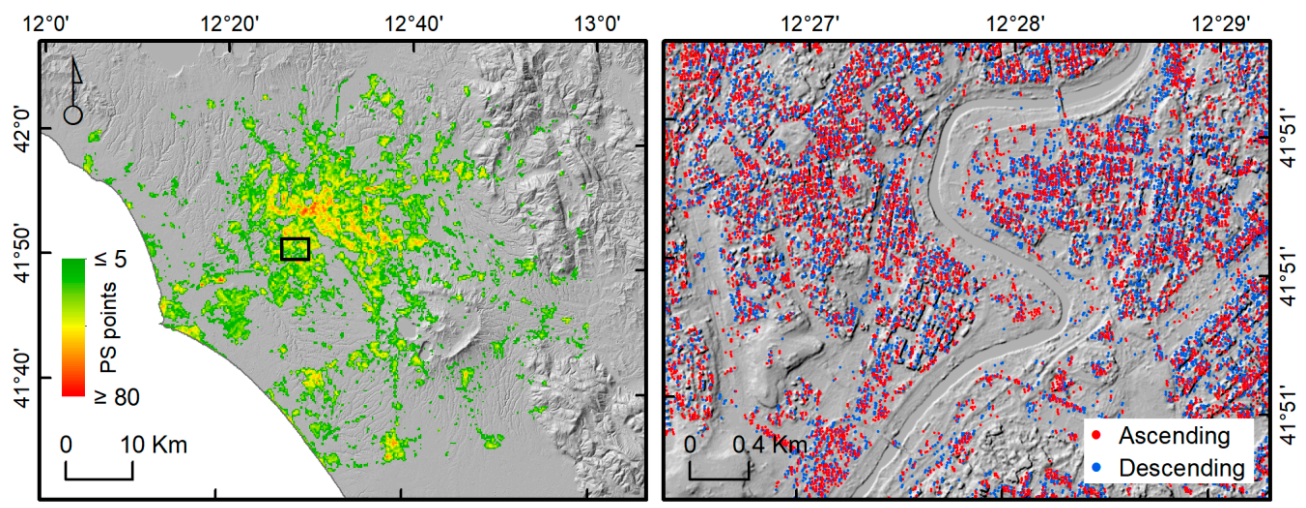

Figure 6. Sentinel-1 PS density over a $200 \mathrm{~m}$ resolution grid (left) and PS locations for both ascending and descending geometries at full resolution. Black square indicates the location of the zoom image shown on the right. ALOS World 3D DSM (left) and CartoSat-1 DSM (right) as backgrounds. 


\subsection{Critical Urban Infrastructures: Global Road Network}

As mentioned in Section 2, we separated the vertical deformation of the different elements such as roads, highways, railways and buildings using the extracted OpenStreetMap shapefile layers available in [31], and here in Figure 7 we show the deformation for the different roads and highways over our AOI. Significant deformation is revealed near the Fiumicino area, along the Tiber River and in the eastern part outside the Grande Raccordo Anulare (GRA). However, other roads show stable behavior or irrelevant deformation.

Systematic monitoring of human infrastructure, particularly critical for communication and transportation (highways, railways, roads, bridges, viaducts) or providing resources (electricity plants, dikes, dams) can be used for maintenance planning activities as well as for infrastructure risk assessment.
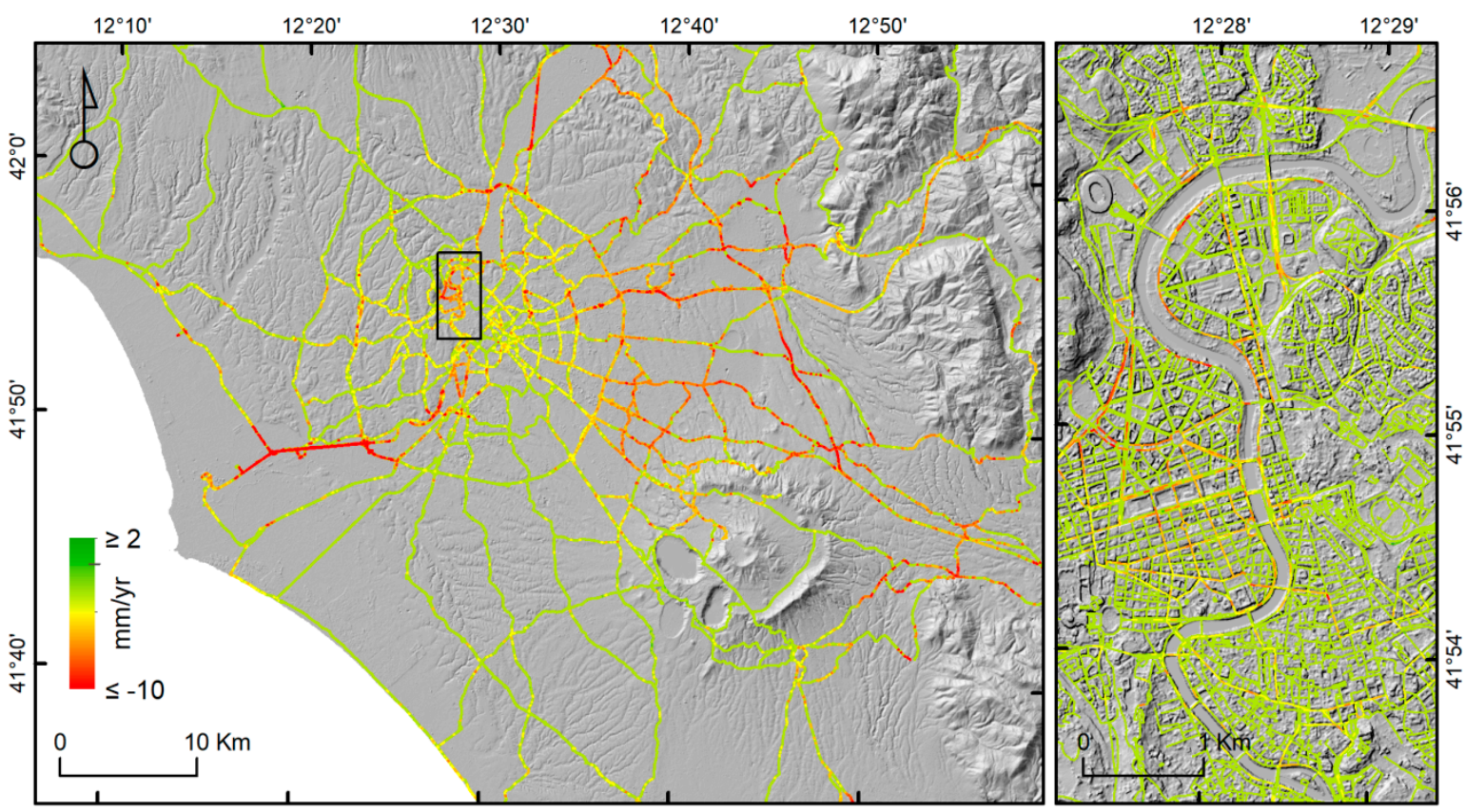

Figure 7. Average vertical motion rates along motorways as well as primary and secondary road networks (left) and a detail over Rome city, including tertiary, residential and pedestrian roads (right). ALOS World DSM (AW3D30) (left) and CartoSat-1 DSM (right) as backgrounds.

\subsection{Subsidence along the Tiber River}

This type of subsidence phenomena is quite common on areas constructed over alluvial deposits along river floodplains.

As mentioned in Section 1.1, the subsidence of buildings on the alluvial sediments along the Tiber River in Rome has been studied using similar techniques. Some notable studies include [11-17]. These all used ERS-1, 2 and ENVISAT ASAR data. The main cause of subsidence in this case is the weight of relatively recent construction on the unconsolidated alluvial material [11-16]. The older constructions in the city center of Rome on the other hand display less movement, as their position has consolidated over time. Findings from the PanGeo project [17], and the studies mentioned above, reported subsidence along the Tiber River and its tributaries determined using PSI and other techniques applied to ERS SAR and ENVISAT ASAR data acquired from 2002 to 2005.

Similar patterns over these alluvial deposits are present in our results (Figure 8). It is difficult to compare the deformation velocities between the studies, due to the different datasets employed and periods analyzed. We measure strong subsidence in several areas such as Ostiense and Santa Victoria quarter, with maximum vertical deformation rate of $-7.2 \mathrm{~mm} / \mathrm{yr}$. Also remarkable is the subsidence 
along the Tiber River and its tributaries (with more than 52k PS points), with a maximum deformation rate of $-8.7 \mathrm{~mm} / \mathrm{yr}$ and an average of $-1.4 \mathrm{~mm} / \mathrm{yr}$.
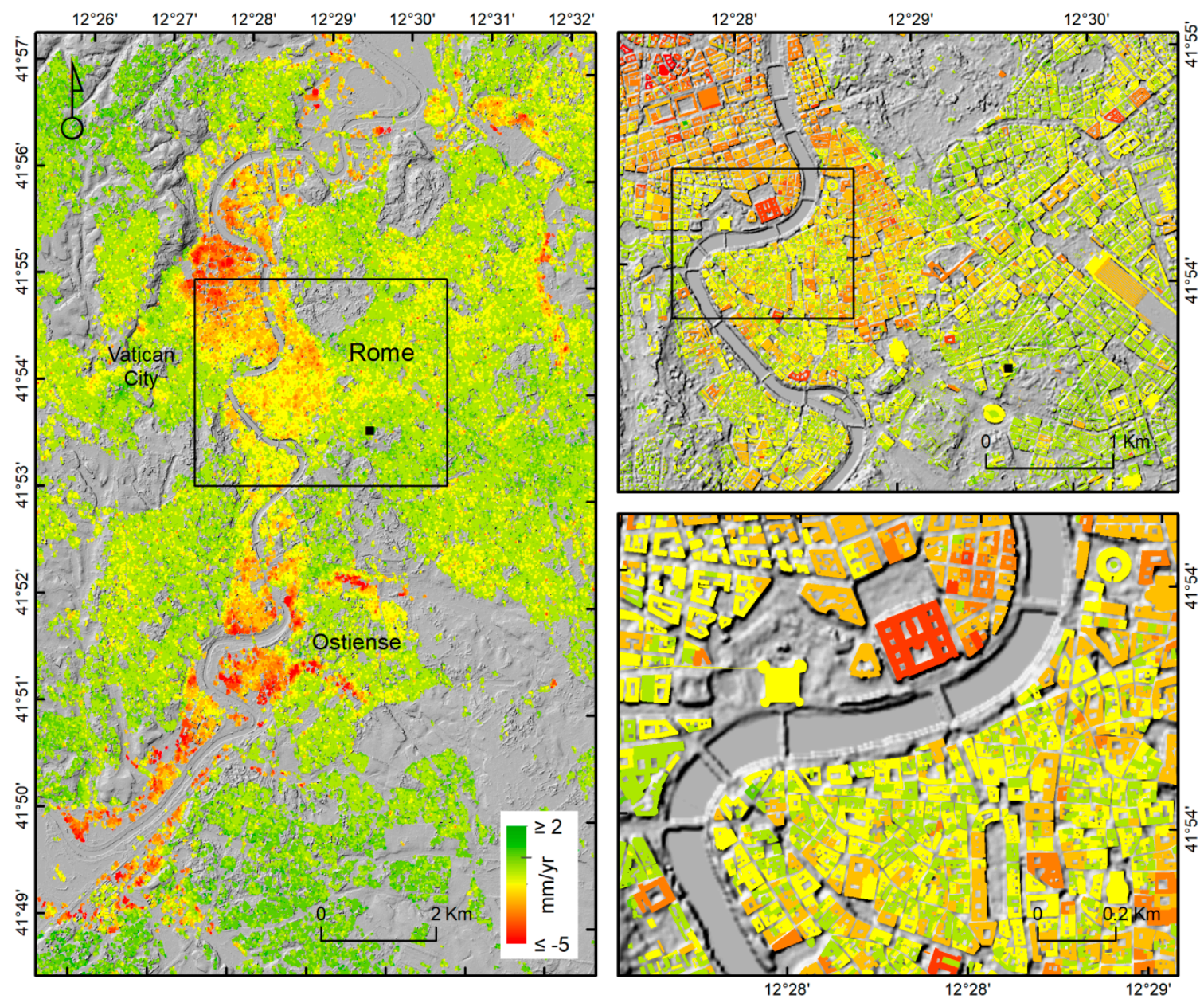

Figure 8. Average vertical deformation rates along the Tiber River and its tributaries (left) and detailed views presenting the estimated maximum deformation rates per building block within the center of Rome (right). The selected reference point (MOSE00ITA EUREF station) is shown in the black square. CartoSat-1 DSM as background.

\subsection{Fiumicino Airport and Ostia Coastal Region}

The deformation over the Fiumicino area is also known, and consistent with previous studies (e.g., [12]), in which similar subsidence patterns are found. There are some points to highlight on the deformation over this area: (i) the airport runway oriented north-south; (ii) the highway; and (iii) the harbor area.

Regarding the runway, part of the track is located over an ancient lake. This has a different degree of consolidation compared to the other part, located over alluvial deposits. A very different behavior is thus shown between the two parts [12]. Also, the highway from Rome towards Fiumicino airport suffers from a high rate of vertical subsidence. This poses a higher risk than comprehensive subsidence over the entire area as large variations in deformation rate can lead to cracks in infrastructures.

Figure 9 illustrates the spatial distribution of the vertical deformation on the Fiumicino area, where the Rome-Fiumicino highway deformation is highlighted in (A), the full time series deformation of a smaller area for both ascending and descending orbits is shown in (B) and in (C) the total accumulated vertical deformation of the portion of highway inside the black ellipse found in (A). Figure $9 \mathrm{C}$ has been obtained by considering the linear velocity of the vertical motion for each PS point inside the dashed lines in Figure 9A from West to East. The horizontal axis is the longitude and vertical axis 
refers to the total accumulated vertical motion. There are visible transitions of blue to red and vice versa between adjacent points, where blue corresponds to no motion or the PS point in that position, as there is not always a PS point per each $20 \mathrm{~m}$ of highway.
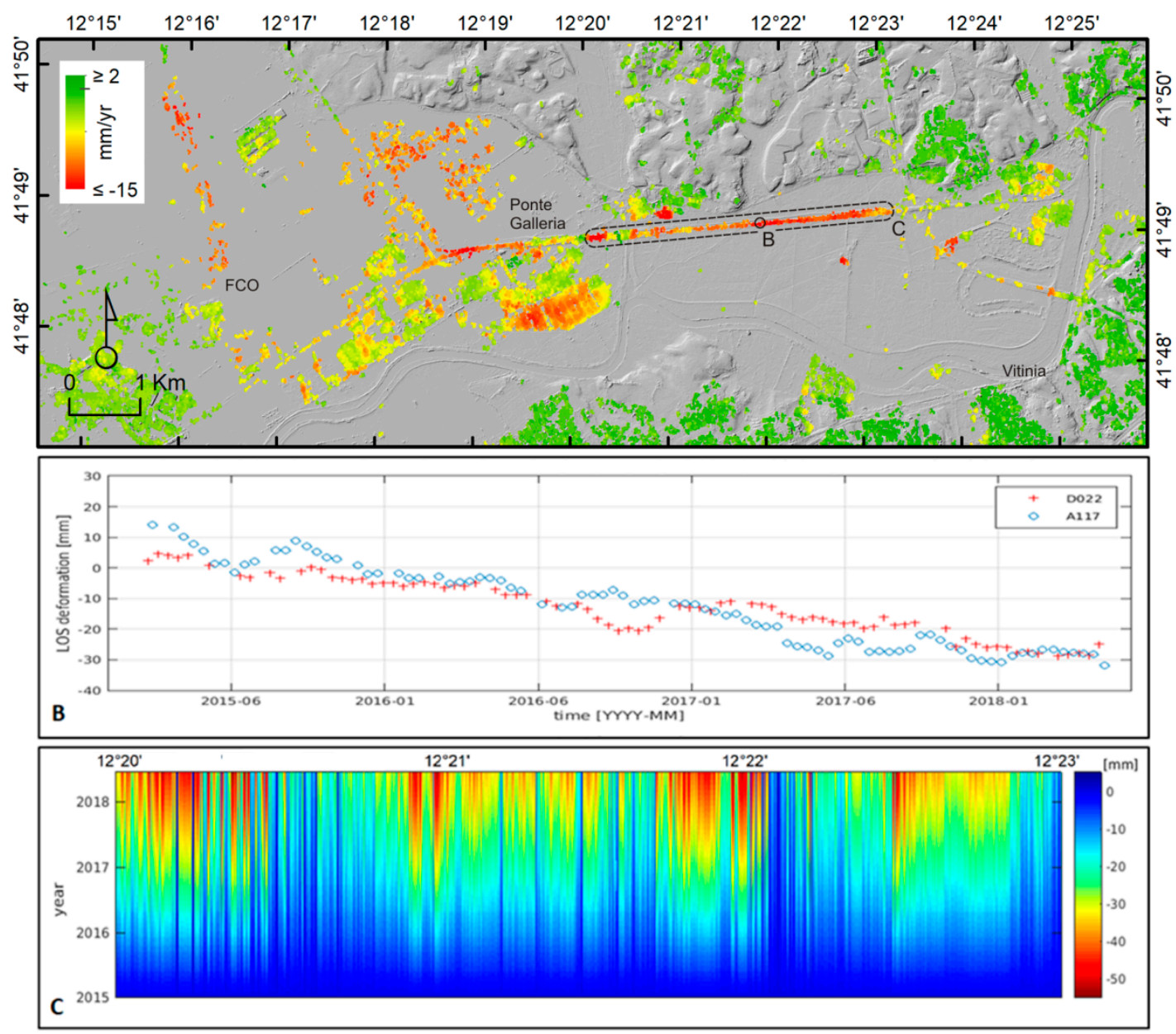

Figure 9. Spatial distribution of average vertical deformation rates at Fiumicino (FCO) airport area overlain on CartoSat-1 DSM (A). PSI LOS displacement time series for selected point target (B) and cumulative motion plot for the Roma-Fiumicino highway $(\mathbf{C})$ are also shown.

Moving from West to East, the first area with strong vertical deformation is near the Mediterranean coast of Ostia-Fiumicino, where more than 20k PS are obtained, measuring a maximum deformation rate of $-9 \mathrm{~mm} / \mathrm{yr}$. Further East, the nearest area with strong deformation is the Fiumicino airport, where only on the airport North-South oriented runway are located 270 PS points, with a maximum vertical deformation of $-14.8 \mathrm{~mm} / \mathrm{yr}$, and an average deformation along the track of $-6.6 \mathrm{~mm} / \mathrm{yr}$. Next to the Fiumicino airport, in the Ponte Galleria industrial area, with more than 3700 PS points, the maximum subsidence value is less than $-19 \mathrm{~mm} / \mathrm{yr}$ while the average vertical deformation is less than $-5 \mathrm{~mm} / \mathrm{yr}$. Continuing towards Rome city, the highway Rome-Fiumicino also suffers strong vertical deformation, having a maximum deformation of $-19 \mathrm{~mm} / \mathrm{yr}$ and an average vertical deformation of almost $-7 \mathrm{~mm} / \mathrm{yr}$.

\subsection{Other Cases of Strong Displacement Patterns}

Other important patterns are found over highways and roads, for which it is worth highlighting that the areas where strong transitions between subsidence rates occur are generally more dangerous as these are responsible for cracks in infrastructures. Hence, these areas with strong variations in 
subsidence behavior, and with high spatial frequency are the ones we would suggest to closely monitor, as well as the areas with significant subsidence, as continuous subsidence may also pose a risk.

In Figure 10, we show an example of the road subsiding while the bridges seem to remain more stable. Specifically, near Settebagni, on the "A1 Diramazione Roma Nord" there are more than 700 PS, measuring a maximum vertical deformation of $-7.8 \mathrm{~mm} / \mathrm{yr}$ with an average of around $-4 \mathrm{~mm} / \mathrm{yr}$.

Finally, on the Eastern part of Rome (see Figure 6), we find Tivoli and Tivoli Terme, with more than $17 \mathrm{k}$ PS, measuring a maximum vertical deformation of $-12 \mathrm{~mm} / \mathrm{yr}$, with an average of $-3 \mathrm{~mm} / \mathrm{yr}$, similar to values obtained in [20].

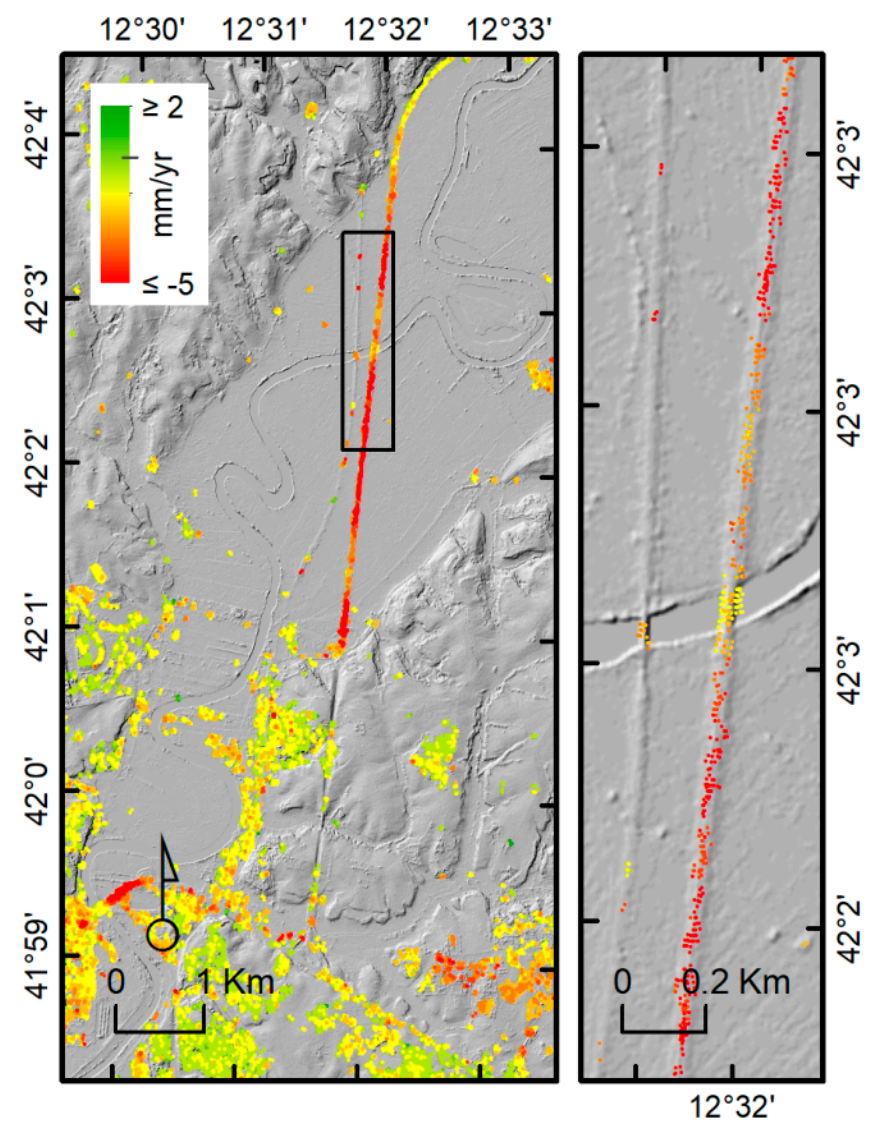

Figure 10. Deformation patterns at the "A1 Diramazione Roma Nord" north of Rome, showing subsidence of alluvial deposits and relative stability of constructed bridges. Geolocation accuracy of the obtained PS results can be visually assessed based on the overlap on the CartoSat-1 DSM in the background.

\section{Discussion}

We present ground deformation in the Rome metropolitan area for the first time, using Copernicus Sentinel-1 mission data and open source toolboxes, paving the way for the broader utilization of the proposed chain by EO practitioners in geohazards applications.

Despite the availability of additional satellite data, limiting the analysis to Sentinel-1A acquisitions (repeat of 12 days) was considered sufficient, given the relatively low deformation rates in the area and the expected linear behavior of motion in time.

The area exhibits diverse deformation patterns, the spatial expression of which indirectly suggests, at least for some cases, the underlying deformation mechanism. The demonstrated quality of interferometric products obtained by Sentinel-1, both in terms of spatial density and uncertainties of displacement estimates is of key importance for the interpretation of motion and the phenomena involved. In our case, the density of the results reaches 1700 point $/ \mathrm{km}^{2}(\sim 70$ PS targets on a $200 \mathrm{~m} \times 200 \mathrm{~m}$ grid) for dense urban centers, 300-600 point $/ \mathrm{km}^{2}$ for the suburban environments, while 
for the entire area of interest we calculated (including areas with no PS) on average 250 point $/ \mathrm{km}^{2}$. It is worth mentioning that we exploit only the co-pol. (VV) channel of Sentinel-1, yet by considering both polarizations $(\mathrm{VV}+\mathrm{VH})$ an increase in the number of PS targets is expected. As a result of the high PS density in built-up areas, and thus, availability of multiple PS targets within each building block, it is possible to differentiate between deformation of the buildings themselves from those related to soil foundations. Yet, given the uncertainties in the location of the PS points and the resolution of Sentinel-1, such separation of motion should be handled with care.

Among the most pronounced deformation patterns is the subsidence at Fiumicino airport reaching $-20 \mathrm{~mm} / \mathrm{yr}$ and along the Tiber River and its tributaries with motion in the order of $-5 \mathrm{~mm} / \mathrm{yr}$. Several other cases with a magnitude of motion worth mentioning, in the range of -12 to $-3 \mathrm{~mm} / \mathrm{yr}$, are found along the coastal zone of Ostia as well as in the Tivoli region. The presence of relatively high deformation gradients for the above mentioned sites is well documented in several studies [11-18,20]. A more detailed analysis is provided in the PanGeo project report about the Geohazard description of Rome [17]. In [20], an analysis integrating geological and hydrogeological modelling provided insights on the relation between ground displacement, variations in the groundwater table and geotechnical properties of the subsoil for the specific case of Fiumicino area. For most of the cases, ground deformation can be attributed to the local geological conditions, such as the compaction of soft sediments, whereas loading by urban constructions should be one of the major reinforcing factors. However, further investigation is required to characterize the on-going subsidence induced phenomena and their temporal evolution compared to past ground displacement measurements.

Computed average vertical displacement rates for the various lithological types, as described in the 1/25,000 scale geological map of Lazio [24] are shown in (Figure 11). As expected, unconsolidated deposits (e.g., sands, clays and other alluvial material) show higher subsidence rates compared to basement formation such as marls, limestones and dolomites.

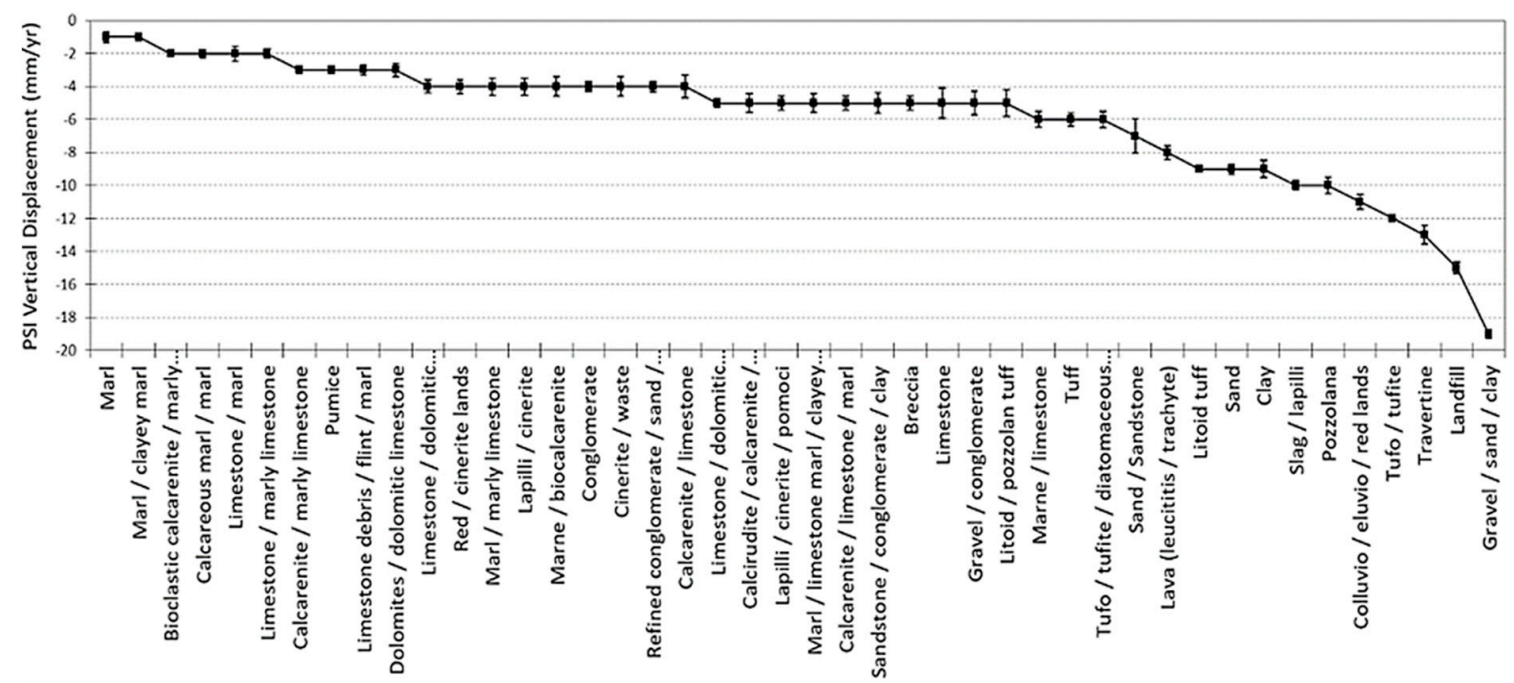

Figure 11. Maximum subsidence rate per soil lithological type in the broader metropolitan area of Rome [31]. Sorted from lower to higher maximum subsidence value.

Deformation over urban infrastructures was also detected, with the case of the GRA, the ring highway surrounding the city of Rome, showing subsidence rates of up to $-7.8 \mathrm{~mm} / \mathrm{yr}$. In fact, the proposed segmentation approach enabled the localization of the deformation along the entire road network of the Rome metropolitan area, a valuable option to support planners.

The above-mentioned findings were verified by inter-comparison with previous studies. Further validation activities were not considered necessary, since InSAR techniques have already undergone a long period of validation [32], confirming their capacity to measure surface motion. Actually, the majority of the observed subsidence has been already reported in the past [11-18]. 
However, the updated status as provided by Sentinel- 1 is of significant importance, since the continuation of ground deformations without addressing any mitigation actions may lead to undesirable consequences in the future.

Finally, our ability to detect and measure ground movements with substantial accuracy within a short time should be underlined. Comparable studies in the past would require long observation periods to collect sufficient satellite data to obtain robust solutions. At the same time, our capacity to actually monitor phenomena has been increased by the systematic availability of the Copernicus Sentinel-1 data.

\section{Conclusions}

We have demonstrated the utilization of open and free data from the Copernicus Sentinel-1 mission using open source toolboxes for advanced interferometric processing. We provide details on a dedicated package for the automation of SNAP-StaMPS PSI processing, which we make available to EO practitioners in response to the growing need for EO-based solutions for monitoring geohazards. The integration of such a chain on a cloud processing environment will enable EO practitioners to respond to the ever-increasing volume of satellite data and high processing capacity requirements.

We verified the results by inter-comparison with previously published studies. To facilitate openness, we have made the PSI measurements over Rome available online, encouraging further analysis and interpretation as well as promoting collaboration between research communities.

Supplementary Materials: The following are available online at http:/ /www.mdpi.com/2072-4292/11/2/129/s1, Sentinel-1 PS LOS displacement rates over the period April 2015-May 2018 in WGS84 projection are provided in Environmental Systems Research Institute (ESRI) shapefile format for both ascending and descending datasets. Each record contains latitude and longitude coordinates in decimal degrees, record identifier, average LOS deformation rates and standard deviation of average LOS deformation rates, both in $\mathrm{mm} / \mathrm{yr}$.

Author Contributions: Conceptualization and methodology, by all authors; software, J.M.D.B., A.H. and M.F.; formal analysis and investigation, J.M.D.B., M.F. and C.S.; writing—review and editing, by all authors; visualization, M.F. and J.M.D.B.

Funding: This research was partly funded by BRGM (www.brgm.fr), in the form of an internal research project.

Acknowledgments: The authors would like to acknowledge the ESA Research and Service Support for the provisioning of the employed computer resources with collocated Copernicus Sentinel-1 data. The suggestions and recommendations by anonymous reviewers that contributed to improving the manuscript are also acknowledged. ALOS World 3D DSM (AW3D30) was downloaded from The Japan Aerospace Exploration Agency (JAXA) and CartoSat-1 DSM was obtained from ESA through the Category-1 research project with ID 42428. Extracted OpenStreetMap layers over Lazio region downloaded from [31].

Conflicts of Interest: The authors declare no conflict of interest.

\section{References}

1. Veci, L.; Lu, J.; Prats-Iraola, P.; Scheiber, R.; Collard, F.; Fomferra, N.; Engdahl, M. The Sentinel-1 Toolbox. In Proceedings of the IEEE International Geoscience and Remote Sensing Symposium (IGARSS), Quebec City, QC, Canada, 13-18 July 2014; pp. 1-3.

2. De Zan, F.; Guarnieri, A.M. TOPSAR: Terrain observation by progressive scans. IEEE Trans. Geosci. Remote Sens. 2006, 44, 2352-2360. [CrossRef]

3. Prats-Iraola, P.; Nannini, M.; Yague-Martinez, N.; Pinheiro, M.; Kim, J.-S.; Vecchioli, F.; Minati, F.; Costantini, M.; Borgstrom, S.; De Martino, P.; et al. Interferometric investigations with the Sentinel-1 constellation. In Proceedings of the 2017 IEEE International Geoscience and Remote Sensing Symposium (IGARSS), Fort Worth, TX, USA, 23-28 July 2017; pp. 5537-5540.

4. Prats-Iraola, P.; Nannini, M.; Yague-Martinez, N.; Scheiber, R.; Minati, F.; Vecchioli, F.; Costantini, M.; Borgstrom, S.; De Martino, P.; Siniscalchi, V.; et al. Sentinel-1 tops interferometric time series results and validation. In Proceedings of the 2016 IEEE International Geoscience and Remote Sensing Symposium (IGARSS), Beijing, China, 10-15 July 2016; pp. 3894-3897.

5. GUNCE, H.B.; SAN, B.T. Measuring Earthquake-Induced Deformation in the South of Halabjah (Sarpol-e-Zahab) Using Sentinel-1 Data on November 12, 2017. Proceedings 2018, 2, 346. [CrossRef] 
6. Ganas, A.; Elias, P.; Bozionelos, G.; Papathanassiou, G.; Avallone, A.; Papastergios, A.; Valkaniotis, S.; Parcharidis, I.; Briole, P. Coseismic deformation, field observations and seismic fault of the 17 November $2015 \mathrm{M}=6.5$, Lefkada Island, Greece earthquake. Tectonophysics 2016, 687, 210-222. [CrossRef]

7. Jelének, J.; Kopačková, V.; Fárová, K. Post-Earthquake Landslide Distribution Assessment Using Sentinel-1 and-2 Data: The Example of the 2016 Mw 7.8 Earthquake in New Zealand. Proceedings 2018, 2, 361. [CrossRef]

8. Hooper, A.; Bekaert, D.; Spaans, K.; Arıkan, M. Recent advances in SAR interferometry time series analysis for measuring crustal deformation. Tectonophysics 2012, 514-517, 1-13. [CrossRef]

9. Foumelis, M.; Delgado Blasco, J.M.; Desnos, Y.-L.; Engdahl, M.; Fernandez, D.; Veci, L.; Lu, J.; Wong, C. ESA SNAP-StaMPS Integrated Processing for Sentinel-1 Persistent Scatterer Interferometry. In Proceedings of the 2018 IEEE International Geoscience and Remote Sensing Symposium, Valencia, Spain, 22-27 July 2018; pp. 1364-1367.

10. Delgado Blasco, J.M.; Foumelis, M. Automated SNAP Sentinel-1 DInSAR Processing for StaMPS PSI with Open Source Tools. Available online: https:/ / zenodo.org/record/1322353 (accessed on 29 July 2018).

11. Stramondo, S.; Bozzano, F.; Marra, F.; Wegmuller, U.; Cinti, F.R.; Moro, M.; Saroli, M. Subsidence induced by urbanisation in the city of Rome detected by advanced InSAR technique and geotechnical investigations. Remote Sens. Environ. 2008, 112, 3160-3172. [CrossRef]

12. Bozzano, F.; Esposito, C.; Mazzanti, P.; Patti, M.; Scancella, S. Imaging Multi-Age Construction Settlement Behaviour by Advanced SAR Interferometry. Remote Sens. 2018, 10, 1137. [CrossRef]

13. Funiciello, R.; Heiken, G.; De Rita, D. I Sette Colli: Guida Geologica a Una Roma Mai Vista; Raffaello Cortina Editore: Milano, Italy, 2006.

14. Cigna, F.; Lasaponara, R.; Masini, N.; Milillo, P.; Tapete, D. Persistent scatterer interferometry processing of COSMO-skymed stripmap HIMAGE time series to depict deformation of the historic centre of Rome, Italy. Remote Sens. 2014, 6, 12593-12618. [CrossRef]

15. Manunta, M.; Marsella, M.; Zeni, G.; Sciotti, M.; Atzori, S.; Lanari, R. Two-scale surface deformation analysis using the SBAS-DInSAR technique: A case study of the city of Rome, Italy. Int. J. Remote Sens. 2008, 29, 1665-1684. [CrossRef]

16. Fornaro, G.; Serafino, F.; Reale, D. 4-D SAR imaging: The case study of Rome. IEEE Geosci. Remote Sens. Lett. 2010, 7, 236-240. [CrossRef]

17. Comerci, V.; Cipolloni, C.; di Manna, P.; Guerrieri, L.; Vittori, E.; Bertoletti, E.; Ciuffreda, M.; Succhiarelli, C. PanGeo: Enabling Access to Geological Information in Support of GMES-D7.1.26 Geohazard Description for Rome. 2012. Available online: http:/ / www.pangeoproject.eu/pdfs/english/rome/Geohazard-Descriptionrome.pdf (accessed on 19 September 2018).

18. Zeni, G.; Bonano, M.; Casu, F.; Manunta, M.; Manzo, M.; Marsella, M.; Pepe, A.; Lanari, R. Long-term deformation analysis of historical buildings through the advanced SBAS-DInSAR technique: The case study of the city of Rome, Italy. J. Geophys. Eng. 2011, 8, S1. [CrossRef]

19. Tapete, D.; Fanti, R.; Cecchi, R.; Petrangeli, P.; Casagli, N. Satellite radar interferometry for monitoring and early-stage warning of structural instability in archaeological sites. J. Geophys. Eng. 2012, 9, S10-S25. [CrossRef]

20. Bozzano, F.; Esposito, C.; Franchi, S.; Mazzanti, P.; Perissin, D.; Rocca, A.; Romano, E. Analysis of a Subsidence Process by Integrating Geological and Hydrogeological Modelling with Satellite InSAR Data. In Engineering Geology for Society and Territory-Volume 5; Springer: New York, NY, USA, 2015; pp. 155-159.

21. Perissin, D.; Wang, T. Repeat-pass SAR interferometry with partially coherent targets. IEEE Trans. Geosci. Remote Sens. 2012, 50, 271-280. [CrossRef]

22. Bekaert, D.P.S.; Walters, R.J.; Wright, T.J.; Hooper, A.J.; Parker, D.J. Statistical comparison of InSAR tropospheric correction techniques. Remote Sens. Environ. 2015, 170, 40-47. [CrossRef]

23. Delgado Blasco, J.M.; Sabatino, G.; Cuccu, R.; Rivolta, G.; Pelich, R.; Matgen, P.; Chini, M.; Marconcini, M. Support for Multi-temporal and Multi-mission data processing: The ESA Research and Service Support. In Proceedings of the 2017 9th International Workshop on the Analysis of Multitemporal Remote Sensing Images (MultiTemp), Brugge, Belgium, 27-29 June 2017.

24. Takaku, J.; Tadono, T.; Tsutsui, K.; Ichikawa, M. VALIDATION of "aW3D” GLOBAL DSM GENERATED from ALOS PRISM. In Proceedings of the ISPRS Annals of the Photogrammetry, Remote Sensing and Spatial Information Sciences, Prague, Czech Republic, 12-19 July 2016. 
25. D'Angelo, P.; Lehner, M.; Krauss, T.; Hoja, D.; Reinartz, P. Towards automated DEM generation from high resolution stereo satellite images. Int. Arch. Photogramm. Remote Sens. Spat. Inf. Sci. 2008, 37, 1137-1342.

26. Scheiber, R.; Moreira, A. Coregistration of interferometric SAR images using spectral diversity. IEEE Trans. Geosci. Remote Sens. 2000, 38, 2179-2191. [CrossRef]

27. Hooper, A.J.; Bekaert, D.; Hussain, E.; Spaans, K. StaMPS/MTI Manual; School of Earth and Environment: Leeds, UK, 2018.

28. EUREF Permanent GNSS Network. MOSE00ITA (Roma, Italy). Available online: http://www.epncb.oma. be/_productsservices / coordinates / crd4station.php?station=M0SE00ITA (accessed on 1 October 2018).

29. Samieie-Esfahany, S.; Hanssen, R.F.; Van Thienen-Visser, K.; Muntendam-Bos, A.; Systems, S. On the effect of horizontal deformation on insar subsidence estimates. In Proceedings of the 2009 Workshop on Fringe, Frascati, Italy, 30 November-4 December 2009.

30. Foumelis, M. Vector-based approach for combining ascending and descending persistent scatterers interferometric point measurements. Geocarto Int. 2018, 33, 38-52. [CrossRef]

31. Estratti OpenStreetmap: Regione Lazio. Available online: https://osm-estratti.wmflabs.org/estratti/ (accessed on 16 September 2018).

32. Crosetto, M.; Monserrat, O.; Cuevas-González, M.; Devanthéry, N.; Crippa, B. Persistent Scatterer Interferometry: A review. ISPRS J. Photogramm. Remote Sens. 2016, 115, 78-89. [CrossRef]

(C) 2019 by the authors. Licensee MDPI, Basel, Switzerland. This article is an open access article distributed under the terms and conditions of the Creative Commons Attribution (CC BY) license (http:/ / creativecommons.org/licenses/by/4.0/). 